\title{
Is there a role for marketing in Community Development?
}

\author{
Abstract \\ Social Marketing is the application of marketing theory to social issues. A significant \\ drawback, though, is that practitioners are encouraged to assume high levels of agency \\ among their target audiences, often while developing programmes aimed at very \\ disadvantaged groups. However, some social marketers work openly and collaboratively at \\ neighbourhood level to co-create change with the people who would usually be cast in the \\ much more passive role of an audience. This article describes a project that adopted these \\ principles, working with people in two deprived neighbourhoods to co-create strategies to \\ reduce risky drinking. Locals used alcohol to cope with feelings of being trapped, \\ emotionally and socially isolated with limited access to employment and facilities. A mobile \\ services hub with a street café was piloted for four days. This project is an example of the \\ potential for overlap between social marketing and Community Development and suggests \\ that practitioners could learn from each other's expertise. The article concludes with a \\ review of social marketing's role in situations where structural barriers to behaviour change \\ are high, finishing with a call for social marketers and community developers to open \\ themselves to collaboration.
}




\section{Introduction}

Marketing has rather an unfortunate image tainted with a whiff of corporate greed, a touch of artificially inflated consumer desires and a Machiavellian willingness to manipulate in pursuit of economic success. Running contrary to this unsavoury reputation, fierce debate has raged within the discipline for at least sixty years about marketing's potential to make a positive contribution to society, accelerated by an article in the Journal of Marketing by Phillip Kotler and Sidney J Levy (1969). Their thesis held that marketing was a pervasive societal activity that could in fact sell citizenship like it could sell soap (see Weibe, 1951). Despite attracting censure at the time, Kotler and Levy's ideas won through and inspired a discipline widely practised today as social marketing (i.e. the application of marketing principles and tools to achieving socially desirable goals, Kotler \& Zaltman, 1971).

This article reflects upon recent developments in the application of social marketing to public health issues. I conclude that a combination of a focus on individual neighbourhoods and the adoption of participatory methods by social marketers creates potential for overlap with community development, providing as an example a project to co-create solutions to the problem of risky drinking in two deprived neighbourhoods. I conclude with a review of the role of social marketing in tackling complex social problems.

\section{What is social marketing?}

Social marketers tend to outline their work as an application of the principles of commercial marketing to achieve socially desirable goals (Donovan, 2011). Two elements of this description probably require further explanation: first, marketing itself; and second, the notion of a socially desirable goal. Jack Trout, an eminent self styled 'Marketing Guru', writes that marketing is 'simply figuring out what you have to do to sell your product or service for a profit' (Trout, 2003, p. 9). The Chartered Institute of Marketing in the UK defines marketing in similar terms, as 'the management process responsible for identifying, anticipating and satisfying customer requirements profitably' (CIM, 2009, p. 2). At its root

then, marketing is said to be about ability to influence human behaviour (Andreasen, 1994) and, as Hastings (2007) points out, this ability has the potential to deliver enormous power to anyone equipped with the relevant skills and knowledge to be a marketer. But rather than using this power for profit, as Mr Trout and the CIM describe, social marketers aim to use it to benefit society. In social marketing therefore, the term 'customer requirements' 
becomes rather more metaphorical than literal, as 'customers' are the targets of a social intervention to influence behaviour; and a customer's 'requirements' translates to an understanding of why they behave in a way that is deemed undesirable (for example, not eating enough fruit and vegetables) combined with an understanding of what might encourage them to make different choices. Specific examples of using marketing in pursuit of socially desirable goals include challenging homophobic attitudes (Hull et al., 2013); reducing the risk of carbon monoxide poisoning (Damon et al., 2013); encouraging children to eat healthily (Stead et al., 2013) and reducing risky drinking among students (Thompson et al., 2013).

As well as delineating social marketing as a sub-discipline of marketing, proponents have been faced with the task explaining to the wider field of behavioural and social change what social marketing is and what differentiates it from other approaches. In attempting to demarcate territory for social marketing in this wider space, scholars have proposed various typologies and markers of identification that have come to be accepted as an orthodoxy for many social marketers. Work by Andreasen (2002) identifies six benchmarks of social marketing that have been widely adopted in other literature (see for example McDermott et al., 2005; Stead et al., 2007): i) that achieving a change in people's behaviour is the ultimate goal against which interventions should be judged; ii) that projects consistently use audience research throughout the intervention process; iii) that target audiences are segmented (i.e. that a heterogeneous population is split into smaller, identifiable groups that share relevant characteristics, so that they may be treated differently); iv) that the creation of attractive exchanges (see Bagozzi, 1975) is a central element of any strategy; v) that all four 'Ps' (Product, Price, Place and Promotion, which in social marketing might be analogous or literal) of the marketing mix are considered in the development of any strategy; and finally vi) that factors that might constitute 'competition' for the desired behaviour change are accounted for. Yet another principle that has featured in the social marketing literature is the notion that any behaviour change must be voluntary (see Grier \& Bryant, 2005). This orthodox definition of social marketing describes a top-down, expert led approach.

\section{Some criticisms of social marketing}


In the previous section, I defined social marketing as the application of marketing principles, such as market segmentation and a customer orientation, to the pursuit of socially desirable outcomes. On the surface, both the theory and the behavioural application of marketing to public health issues like healthy eating, smoking cessation and consuming alcohol responsibly is relatively straightforward. Certainly, if social marketing is equated with producing a creative communications campaign, like Change4Life (DH, 2013) for example, with cleverly worded messages and innovative use of the media then life for a social marketer is simple. However, the difficulty with campaigns that rely primarily on communication is that they are predicated on the assumption that the target audience is composed of rational individuals who can be persuaded, cajoled, shamed, frightened, into making significant and permanent lifestyle changes. This approach emphasizes individual agency over structural factors, which is a problem because a great many of the changes in behaviour that policy makers would like to see are simply too complex to be solved by concentrating solely on the choices of individuals in the absence of any consideration of structure (Stokols, 1994; Goldberg, 1995; Hastings et al., 2000; Andreasen A. R., 2006). A particular conundrum is Hastings' (2003) observation that frequently, we are tasked with targeting the most at risk (Pechmann et al., 2011) disempowered and hard-to-reach 'customers' in society; whereas commercial marketers, who are allowed much greater freedom and flexibility (Heskett, 1986), tend to ignore such customers with impunity (to the extent that they can actually exacerbate their exclusion). It is when social marketers are commissioned to tackle complex issues that relate to deprivation and inequality that the potential for overlap with community development comes to the fore. The next section elaborates.

\section{Health inequality and neighbourhood interventions}

There is widespread consensus in the literature that the worse someone's socio-economic position, the worse their health is likely to be (Graham, 2007). There are numerous factors that contribute to health inequality, many of which are shaped by broad social, political and economic forces (CSDH, 2008) such as housing policy and access to health and social care (see Bambra et al., 2010, for a review). However, in addition to the impact of these structural factors, it has been observed that certain geographic areas are associated with greater health inequality (Atkinson \& Kintrea, 2001). As well as lower life expectancy (Shaw 
et al., 2005), residents of these deprived neighbourhoods have a low sense of belonging, fear for their personal security, low expectations of mutual support from neighbours (Meegan \& Mitchell, 2001) and low self-worth (Kawachi, 2000). The way this exclusion is concentrated spatially, allied to the stigma associated with living in such a neighbourhood, is believed to exacerbate powerlessness because spaces themselves exist to function as units of state organisation and power (Madanipour, 1998). For these reasons, it can be argued that it is both unfair and counterproductive implicitly to blame individuals experiencing this inequality for their 'bad' lifestyle choices (Marmot, 2010; Green, 1984) by targeting them with broad brush social marketing strategies predicated upon high levels of individual agency.

Therefore, in addition to national policies to combat the structural factors that reinforce health inequality, interventions at neighbourhood level also make theoretical, practical and economic sense. Partly due to the consensus that highest health need is often concentrated in deprived neighbourhoods (Atkinson \& Kintrea, 2001), and therefore intervention and service delivery is most effective when organized spatially (Raco \& Flint, 2001). As well as these practical considerations, models that attempt to account for the interaction of social, environmental and cultural factors, such as social ecology (e.g. see Collins et al., 2010) appear to lead inexorably to the conclusion that any intervention hoping to influence behaviour must account for this ecological complexity and in many cases that means accounting for differences at neighbourhood level. And so for all the reasons outlined above, social marketing projects that are aimed specifically at one or two neighbourhoods are becoming increasingly common. Working at neighbourhood level places social marketers partly in community development territory; but even more commonality between the disciplines can be found when social marketers explore participatory methods at the same time, as explained in the next section.

\section{Participatory approaches in social marketing}

The first section provided the orthodox definition of social marketing, based upon the broad assumption that social marketers attempt to act upon a target audience, informed by research, rather than working openly with them. However, theory is evolving to encompass new ideas from a number of disciplines and of particular interest given social marketing's commercial heritage is the emergent body of work that has come to be known broadly as 
'co-creation of value', i.e. collaborating with customers for mutual benefit (Schau et al., 2009). In this context, value is based upon the subjective experiences of individuals rather than defined in straightforward economic terms (see Vargo \& Lusch, 2008) and should not be conflated with personal or cultural values. For example, the way that Salomon, a manufacturer of winter sports equipment, collaborated with the snowboarding 'tribe' openly by encouraging snowboarders to co-design the equipment and providing support for competitions and events without attempting to sell to the community (see Cova \& Cova, 2002).

Because of the collaborative focus inherent in co-creation as a method of intervention design, social marketers' interest in participatory methods has been piqued (Collins et al., 2012). Collaborative approaches are woven through a variety of disciplines in the social and health sciences, such as critical pedagogy (Kemmis \& McTaggart, 2005; Freire, 2000); public health (Israel et al., 1998); community development (Fals-Borda \& Rahman, 1991); theology (Berryman, 1987) and international development (Chambers, 1997; Hickey \& Mohan, 2005). The basic principle of involving participants in research as partners rather than conceptualising them as passive subjects seems fairly consistent across these disciplines, despite subtle differences in terminology and technique. Participatory research in public health (for example, Community-Based Participatory Research, see Minkler, 2004) can be traced back through critical reflections upon the problem of health inequality related to powerlessness and poverty (Israel et al., 1998), via a concurrent interest in social epidemiology (Krieger, 2001).

Of course, whilst these methods offer thought-provoking new directions for social marketing, they have a longstanding association with the ambition of community developers to overcome 'poverty and disadvantage, knitting society together at the grass roots and deepening democracy', (CLG, 2010), p.13). The approach that appears to have most in common with recent innovations in social marketing practice has been categorized by (Hickey \& Mohan, 2005, p.242) as 'populist', emphasising the role of the target audience (in marketing parlance) as knowledgeable and capable and repositioning agents as facilitators rather than as experts leading change from the top. Formalized frameworks like Community-Based Prevention Marketing (Bryant et al., 2007) for example, seek to integrate ideas from community capacity-building, behavioural theories and marketing tools and 
concepts. In these and other ways, social marketers have learnt from community development. An example of this way of working can be found in a recent project, commissioned as a social marketing intervention by a Primary Care Trust in England. The following sections describe the project in depth.

\section{Social marketing project to co-create ways to reduce risky drinking}

The project aimed to understand why adults in two very deprived urban neighbourhoods engaged in risky drinking practices and to co-create interventions to help them cut down. At the outset, it was assumed that providing information or attempting to educate people would probably be ineffective. Instead, it was supposed that many factors in the social, economic and physical environment (such as access to employment) would influence drinking levels and that any intervention would need to acknowledge these.

As with any participatory research project, we followed a cyclical process of planning, action, reflection and planning (Kemmis \& McTaggart, 2005); beginning with asset mapping to identify networks, organisations and influential people. The intended next step was to cocreate research methods with participants followed by a period of fieldwork. The nature of participatory methods is such that the further into the future one attempts to plan, the more vague those plans must be, thus, the latter stages of the project were simply designated 'co-analysis' and 'co-design'.

\section{Co-research}

Co-creation of the data collection methods began via 'methods stations', which encouraged people to experiment with different ways of expressing themselves about risky drinking in context such as visual methods, playing simple games and more traditional talk-based approaches and then giving feedback on their suitability. The methods stations were taken to various community settings over the course of 6 weeks.

In some cases we found that the informality of the ad hoc discussions in public, familiar surroundings gave participants a feeling of security, but many were concerned that they would 'lose control' of their stories; there seemed to be a distrust of authority and outsiders and whilst we had mitigated this somewhat by spending time in the community, the capital we had created didn't extend beyond the researcher. Consequently, the methods cocreation evolved naturally into an ethnographic style of data collection: between January 
and June 2012, a researcher spent time in multiple venues across both communities and collected over 48,000 words of field notes based on conversations with local people. The research questions were: i) Why do people drink? ii) Why do they feel they can't stop and iii) How does this affect them and those around them?

\section{Co-analysis}

Because there were significant challenges associated with engaging participants beyond adhoc informal conversation, two academic researchers undertook the majority of the analysis with some input from participants after the effect. Field notes relating to conversations with twenty three males and forty one females in one neighbourhood, and nineteen males and thirty nine females in the other were collected. Of these only fourteen gave written consent to be quoted, the others consented verbally to their stories being used as anonymous background information and are only identified in field notes by gender and approximate age. First, the two researchers performed a thematic analysis (Braun \& Clarke, 2006) on the field notes from the first neighbourhood, starting by reviewing the data independently to generate initial codes. Next, they compared their interpretations of the data and codes to create initial themes. Each theme was reviewed, discussed, edited and given a single word to describe it. Then, the data and original codes were reviewed against the named themes to check consistency with the overall story of the data. For each theme, a graphic illustration and brief description was created, which were used to reflect our interpretations back to people in the neighbourhood. The themes were: Family; Trapped; Worry; Apathy (which people asked us to change to Powerless); Alone; Ashamed and Confused. Themes integrated a range of factors: from significant structural barriers like housing regulations to individual obstacles like mental health, all of which were woven through participants' stories.

Many people felt trapped by their responsibilities, their social and financial situation and in many cases physically trapped by unemployment or their inability to move due to restrictive regulations governing social housing. Numerous participants felt stuck in a rut, suffering mental health or mood problems or were simply bored and de-motivated: powerless. Consequently, they felt alone; physically, emotionally and socially isolated. 
'Like I'm totally on my own, and nobody would care if I turned up stiff tomorrow. I've lost my kids and my friends and family... It all just makes you feel like you're worthless and that whatever you do it'll end the same way.' (Female, 40s)

Stories of domestic violence, with participants as perpetrators and victims, were distressingly common; all these feelings explain why many participants found themselves using alcohol to cope.

'And you want to keep it to yourself, it's shaming especially when you get bruises ... they can start having a drink just to help them cope with it all.' ("Michelle", 40s)

Finally, as well as the overall themes, we found that males and females and younger and older people experienced these issues in distinctive ways.

'It's even harder for men to deal with something like that... I just wanted to numb it all and wake up when it was all over. I wasn't a good husband' (male, late 50s) To communicate this to local people, one of the researchers wrote four case study stories that described a typical person from each of these groups, based upon an anonymized amalgamation of the findings. After the themes were discussed with the people from the first neighbourhood, data from the second neighbourhood were reviewed against the themes. We found that the original themes were representative of the second neighbourhood as well, but that feelings of isolation (alone) and being trapped came through more strongly in the second neighbourhood than the first.

"When you move in and you're already labelled, that's what I can't stand"... One of her neighbours also frightened her - he had shot at her with an air rifle, put a samurai sword through her front door... (Reported speech and anonymous quote from female participant, second neighbourhood)

Despite a positive response from participants and stakeholders, local involvement in the project was much less than we had hoped, hampered by a number of factors: cynicism or 'participation fatigue' created in part by the number of short-term projects that had been set up and then disappeared once funding had been withdrawn, exacerbated by the feeling that outsiders with their 'five-a-day' messages didn't understand what it was like to live in the community. Distrust of authority in general and an almost pathological fear of social services' involvement in family life was a further barrier. 
'You see all the women outside school and it's obvious some of them have been drinking... And then they're scared someone's going to pass that on, that social services might step in.' (Female, 20s)

\section{Co-design}

Following the data collection and interpretation, various activities were undertaken in the neighbourhoods, reflecting interpretations back to them and using creative techniques (like asking participants to imagine they had a superpower or a cheque for $£ 1,000,000$ ) to elicit their suggestions. Ideas evolved differently in the two neighbourhoods. In the first, more than forty ideas emerged from a workshop attended by a small core of community volunteers; resonating with the principle of segmentation, some were quite specific to a particular age and life-stage (e.g. extreme sports could help divert groups of young men from organising all their social activity around alcohol) but possessed characteristics that apply to all (e.g. provide activities that don't revolve around drinking). These ideas coalesced into a vision for a Hub that would host a range of services for all ages as well as being a venue for 'positive' (i.e. non stigmatising) reasons to visit. Currently, this idea is being considered as part of wider development work in the area.

In the second neighbourhood, participants articulated feelings of being let down and forgotten; further, the co-design activity reinforced the impression that people do not tend take part in anything that requires them to leave their own territory. Ideas from co-creators were based primarily around structural factors like access to services, as well as ideas to build community strength, such as breaking down barriers and reducing isolation. These suggestions were unified into the concept of mobile services that would be invited into the neighbourhood. A four-day pilot staffed by volunteers from the neighbourhood and service providers included themes of community engagement, finances, young people and mental health. A street café was provided on each day, and all equipment was donated for use in future events.

\section{Conclusions}

Turning back to the marketing academics of the 1960s, it seems that critics of the foundational work that led to the field of social marketing may have had a point. They were not concerned about the validity of applying marketing ideas to social problems; instead, 
they were uneasy about the implications of broadening the definition of marketing beyond commerce because new boundaries were ill defined. Thus, their concern that if a task is performed, anywhere by anybody, that has some resemblance to a task performed in marketing, that would be marketing' (Luck, 1969, p. 53). The implication being that anyone considering how to best get their point across to an audience, any development worker trying to plan how best to empower people by building their capacity to effect change in their own communities could, theoretically, be identified as practising marketing. Recent innovations in co-created social marketing leave us facing the same issues: if projects that work openly and collaboratively with neighbourhoods and communities to effect change can be identified and commissioned as social marketing, then how does this fit with existing work in community development? Where do the boundaries lie?

\section{Discussion and implications}

The case in this article is one of the more extreme examples of the potential for overlap between social marketing and community development, due to the high levels of deprivation in the two neighbourhoods and the way that the target behaviour change (i.e. drinking) was so bound up with structural inequality. But what power can a social marketer exercise in such circumstances; how can they begin to tackle these structural barriers, particularly when a funder has commissioned a project with specific behavioural outcomes? In this case, our power was located in the depth of the research we had conducted, the strength of the relationships we had formed with local stakeholders and in their belief that our work had served to legitimise what they had been trying to say all along: we had helped to strengthen local assets by reinforcing the appropriateness of the work they were trying to do. But I think this is a relatively atypical example.

The conventional form of social marketing as defined earlier in this article is ill equipped to challenge structural inequality because of the explicit emphasis on voluntary behaviour change. Social marketers know this and have responded to the challenge it poses in two distinct ways: one approach recommends that social marketing, as a 'brand of individual behaviour change' (Andreasen, 2002, p. 8), should only be used in situations where individual change, rather than structural change or community mobilization, is an appropriate goal. From this perspective, the case I describe should not be labelled social marketing at all because social marketers cannot realistically promise to deliver a sustained 
change in individual drinking behaviour when the structural barriers are so significant. However, an alternative has emerged more recently with the rather radical suggestion of a Total Market Approach (TMA), inspired in part by the work of the Stanford Center for Social Innovation (Phils et al., 2008) and defined as 'the application of marketing principles to shape markets that are more effective, efficient, sustainable and just' in advancing social welfare (Lefebvre, 2012, p. 120). Lefebvre conceptualises society as a marketing system, liberating social marketers to call upon a range of strategies such as communication, regulation, finance and community mobilization; in fact, any technique that might advance social welfare 'through the application of marketing principles' (p. 120) is fair game. It could be argued that this approach conceptualises social marketing as integral to the policy process, rather than a mechanism for behavioural change brought in at the end.

It seems relevant here to offer an observation about the difference between the way commercial and social marketers position themselves in the hierarchy of their respective spheres: On the one hand, much social marketing theory is positioned as a tool to be wielded by heavyweights like epidemiologists and policymakers. Commercial marketers, on the other hand, demand a seat at the boardroom table. Lefebvre appears to be proposing that social marketers ape their commercial counterparts in asking to be promoted to conductor of the orchestra of disciplines whose aim is to improve people's lives. If social marketers were in this strategic position, integrated with the entire policy process, then hypothetically they could ask for changes to housing policy, large-scale investment in adult education programmes, better support of young mothers and people struggling with mental and physical health problems in deprived areas. They could develop efficient, low-cost public transport and invest in organisations working to build community capacity. Which would probably reduce risky drinking in those neighbourhoods somewhat.

Amid what may be growing consternation among the readers of this article that social marketers are secretly plotting world domination, it will be reassuring to hear that while there is merit in a theoretical exploration of the TMA, most social marketers recognise that public policy is considerably more complex to 'market' than a commercial product or service; not to mention the fact that such activities are the preserve of democratically elected officials, not behaviour change theorists. However experiences with this project suggest that in complex situations, especially those involving structural inequality, using 
social marketing as a tool for creating glib messages like the iconic 'five-a-day' campaigns so despised by the participants in this study, messages that gloss over structural inequality, is so likely to fail as to represent a senseless waste of resources. Social marketers, in my opinion, cannot ethnically accept sole commissions on these terms. Conversely, in these situations it seems eminently sensible for social marketers to collaborate with other experts, like community developers and local government, if they are commissioned to tackle behaviours that are symptomatic of deprivation and inequality. Social marketing's role in such a collaboration could be to focus explicitly upon one or two measurable behaviour changes that need not necessarily be related to inequality and to hone in on particular 'segments' of the population, working out what that group values and finding a way to deliver it, like the young men and their extreme sports to divert them from drinking on every social occasion. Marketers can also bring to bear new skills, such as branding and communication, service design and social media. For instance a 'pub' providing traditional pub games and a caring landlord to keep an eye on older male drinkers could have been launched. There are yet no precise answers as to how such an alliance could be organised; so in conclusion, I call upon community developers and social marketers to pool knowledge and resources, set aside the comfort of single disciplinary working and open their minds to collaboration.

\section{Acknowledgements}

The author extends sincere thanks to Jo Howard, Mick Carpenter and the anonymous reviewers for their constructive suggestions to improve the article.

\section{Funding statement}

The Public Health Directorate at NHS Gloucestershire commissioned a project led by the author aimed at understanding the causes of and possible solutions to reducing risky drinking in the district with the highest rate of alcohol related hospital admissions in the county.

\section{References}

Ajzen, I., \& Madden, T. J. (1986). Prediction of goal-directed behavior: Attitudes, intentions, and perceived behavioral control. Journal of experimental social psychology, 22 (5), 453-474. 
Andreasen, A. R. (2002). Marketing Social Marketing in the Social Change Marketplace. Journal of Public Policy \& Marketing, 21 (1), 3-13.

Andreasen, A. R. (2006). Social marketing in the 21st century. London: Sage Publications.

Andreasen, A. R. (1994). Social Marketing: Its definition and domain. Journal of Public Policy \& Marketing, 13 (1), 108-114.

Atkinson, R., \& Kintrea, K. (2001). Disentangling Area Effects: Evidence from Deprived and Non-deprived Neighbourhoods . Urban Studies, 38 (12), 2277-2298.

Bagozzi, R. P. (1975). Marketing as Exchange. Journal of Marketing, 39 (4), 32-39.

Bambra, C., Gibson, M., Sowden, A., Wright, K., Whitehead, M., \& Petticrew, M. (2010). Tackling the wider social determinants of health and health inequalities: evidence from systematic reviews. Journal of Epidemiology and Community Health, 64, 284291.

Berryman, P. (1987). Liberation Theology: essential facts about the revolutionary movement in Latin America and beyond. Philidelphia: Temple University Press.

Braun, V., \& Clarke, V. (2006). Using thematic analysis in psychology. Qualitative Research in Psychology, 3 (2), 77-101.

Bryant, C. A., McCormack Brown, K. R., McDermott, R. J., Forthofer, M. S., Bumpus, E. C., Calkins, S. A., et al. (2007). Community-Based Prevention Marketing : Organizing a Community for Health Behavior Intervention. Health Promotion Practice, 8, 154-163.

Chambers, R. (1997). Whose reality counts? Putting the first last. London: Intermediate Technology Publications.

Chaskin, R. J. (1997). Perspectives on Neighbourhood and Community: A Review of the Literature. Social Service Review , 521 - 547.

CIM. (2009). Marketing and the 7Ps: A brief summary of marketing and how it works . Retrieved 2013 йил 09-04 from www.cim.co.uk: http://www.cim.co.uk/files/7ps.pdf

CLG. (2010). www.communities.gov.uk. Retrieved 2012 йил 10-10 from http://www.communities.gov.uk/documents/statistics/pdf/1871208.pdf

Collins, K., Spotswood, F., \& Manning, L. (2012). Poverty, Power and Politics: Considerations for Engaging Citizens in Social Marketing Programmes". Using Social Marketing to Deliver Effective and Efficient Citizen Focused Social Programmes; . European Social Marketing Conference. Lisbon.

Collins, K., Tapp, A., \& Pressley, A. (2010). Social Marketing and social influences: Using social ecology as a theoretical framework. Journal of Marketing Management, 26 (13-14), 1181-1200.

Cova, B., \& Cova, V. (2002). Tribal Marketing: The Tribalisation of Society and Its Impact on the Conduct of Marketing. European Journal of Marketing, 36 (5-6), 595-620.

CSDH. (2008). Closing the gap in a generation: health equity through action on the social determinants of health. Final Report of the Commission on Social Determinants of Health. Geneva: World Health Organization. 
Damon, S. A., Poehlman, J. A., Rupert, D. J., \& Williams, P. N. (2013). Storm-Related Carbon Monoxide Poisoning: An Investigation of Target Audience Knowledge and Risk Behaviors . Social Marketing Quarterly (19), 188-199.

DH. (2013). Change4Life. (D. o. Health, Producer) Retrieved 09 13, 2013 from http://www.nhs.uk/change4life/Pages/change-for-life.aspx

Donovan, R. (2011). Social marketing's mythunderstandings . Journal of Social Marketing, 1 (1), 8-16.

Fals-Borda, O., \& Rahman, M. A. (1991). Action and Knowledge: Breaking the monopoly with Participatory Action Research. London: Intermediate Technology Publications.

Freire, P. (2000). Pedagogy of the Oppressed. London: Continuum International Publishing Group.

Goldberg, M. E. (1995). Social Marketing: Are We Fiddling While Rome Burns? Journal of Consumer Psychology, 4 (4), 347- 370.

Graham, H. (2007). Unequal lives: health and socioeconomic inequalities. Maidenhead: Open University Press,.

Green, L. (1984). Modifying and Developing Health Behaviour. Annual Review Public Health, 5, 215-236.

Grier, S., \& Bryant, C. A. (2005). Social Marketing in Public Health. Annual Review of Public Health, 26, 319-39.

Hastings, G. (2003). Competition in Social Marketing. Social Marketing Quarterly, 4 (3), 6-9.

Hastings, G. (2007). The diaspora has already begun. Marketing Intelligence \& Planning, 25 (2), 117-122.

Hastings, G., MacFadyen, L., \& Anderson, S. (2000). Whose Behavior is it Anyway? The Broader Potential of Social Marketing. Social Marketing Quarterly, 6 (2), 46-58.

Heskett, J. L. (1986). Managing in the service economy . Boston: Harvard Business School Press.

Hickey, S., \& Mohan, G. (2005). Relocating participation within a radical politics of development. Development and Change, 36 (2), 237-262.

Hull, S. J., Gasiorowicz, M., Hollander, G., \& Short, K. (2013). Using Theory to Inform Practice: The Role of Formative Research in the Construction and Implementation of the Acceptance Journeys Social Marketing Campaign to Reduce Homophobia . Social Marketing Quarterly (19), 139-155.

Israel, B. A., Schulz, A. J., Parker, E. A., \& Becker, A. B. (1998). Review of Community-Based Research: Assessing Partnership Approaches to Improve Public Health. Annual Review of Public Health, 19, 173-202.

Kawachi, I. (2000). Income inequality and health. In L. Berkman, \& I. Kawachi, Social epidemiology (pp. 76-94). Oxford: Oxford University Press.

Kemmis, S., \& McTaggart, R. (2005). Participatory Action Research. In N. K. Denzin, \& Y. S. Lincoln, The Sage Handbook of Qualitative Research (3rd Ed.) (pp. 559-605). London: Sage Publications Inc. 
Kotler, P., \& Levy, S. J. (1969). Broadening the Concept of Marketing. Journal of Marketing, 33, 10-15.

Kotler, P., \& Zaltman, G. (1971). Social Marketing: An Approach to Planned Social Change. Journal of Marketing, 86, 3-12.

Krieger, N. (2001). Theories for Social Epidemiology in the 21st Century: an Ecosocial Perspective. International Journal of Epidemiology, 30, 668-677.

Lefebvre, R. C. (2012). Transformative social marketing: co-creating the social marketing discipline and brand. Journal of Social Marketing, 2 (2), 118-129.

Luck, D. (1969). Broadening the Concept of Marketing - Too Far. Journal of Marketing, 33, 53-63.

Madanipour, A. (1998). Social exclusion and space. In G. C. A. Madanipour, Social Exclusion in European Cities (pp. 75-94). London: Jessica Kingsley Publishers.

Marmot, M. (2010). Fair society, healthy lives: the Marmot Review: Strategic review of health inequalities in England post-2010. London: ISBN 9780956487001.

McDermott, L., Stead, M., \& Hastings, G. (2005). What Is and What Is Not Social Marketing: The Challenge of Reviewing the Evidence. Journal of Marketing Management Volume, 21 (5-6), 545-553.

Meegan, R., \& Mitchell, A. (2001). 'It's Not Community Round Here, It's Neighbourhood': Neighbourhood Change and Cohesion in Urban Regeneration Policies. Urban Studies, 38 (12), 2167-2194.

Minkler, M. (2004). Ethical Challenges for the "Outside" Researcher in Community-Based Participatory Research. Health Education Behaviour, 31, 684 .

Pechmann, C., Moore, E., Andreasen, A., Connell, P., Freeman, D., Gardner, M., et al. (2011). Navigating the central tensions in research on at-risk consumers: challenges and opportunities. Journal of Public Policy \& Marketing, 30 (1), 23-30.

Phils, J. J., Deiglmeier, K., \& Miller, D. (2008). Rediscovering social innovation. Stanford Social Innovation Review, Fall, 34-43.

Raco, M., \& Flint, J. (2001). Communities, places and institutional relations: assessing the role of area-based community representation in local governance. Political Geography, 20, 585-612.

Schau, H. J., Muñiz, A. M., \& Arnould, E. J. (2009). How Brand Community Practices Create Value. Journal of Marketing, 73 (5), 30-51.

Shaw, M., Davey Smith, G., \& Dorling, D. (2005). Health inequalities and New Labour: how the promises compare with real progress. BMJ, 330, 1016-21.

Stead, M., Arnott, L., \& Dempsey, E. (2013). Healthy Heroes, Magic Meals, and a Visiting Alien: Community-Led Assets-Based. Social Marketing Social Marketing Quarterly, 19, 26-39.

Stead, M., Gordon, R., Angus, K., \& McDermott, L. (2007). A systematic review of social marketing effectiveness. Health Education, 107 (2), 126-191. 
Stokols, D. (1994). Translating social ecological theory into guidelines for health promotion. . American Journal of Health Promotion, 10 (4), 282-298.

Thompson, E. B., Heley, F., Oster-Aaland, L., Stastny, S. N., \& Crawford, E. C. (2013, March). The Impact of a Student-Driven Social Marketing Campaign on College Student Alcohol-Related Beliefs and Behaviors. Social Marketing Quarterly , 52-64.

Trout, J. (2003). A Genie's wisdom: A fable of how a CEO learned to be a marketing genius. New Jersey: John Wiley \& Sons.

Vargo, S. L., \& Lusch, R. F. (2008). Service-dominant logic: continuing the evolution. Journal of the Academy of Marketing Science, 36 (1), 1-10.

Weibe, G. (1951). Merchandising Commodities and Citizenship on Television . The Public Opinion Quarterly, 15 (4), 679-691. 